\title{
Determination of Biological Age: Geriatric Assessment vs Biological Biomarkers
}

\author{
Lucas W. M. Diebel ${ }^{1,2} \cdot$ Kenneth Rockwood ${ }^{1,2,3}$ \\ Accepted: 20 May 2021 / Published online: 16 July 2021 \\ (C) The Author(s), under exclusive licence to Springer Science+Business Media, LLC, part of Springer Nature 2021
}

\begin{abstract}
Purpose of Review Biological age is the concept of using biophysiological measures to more accurately determine an individual's age-related risk of adverse outcomes. Grading of the degree of frailty and measuring biomarkers are distinct methods of measuring biological age. This review compares these strategies for estimating biological age for clinical purposes.

Recent Findings The degree of frailty predicts susceptibility to adverse outcomes independently of chronological age. The utility of this approach has been demonstrated across a range of clinical contexts. Biomarkers from various levels of the biological aging process are improving in accuracy, with the potential to identify aberrant aging trajectories before the onset of clinically manifest frailty.

Summary Grading of frailty is a demonstrably, clinically, and research-relevant proxy estimate of biological age. Emerging biomarkers can supplement this approach by identifying accelerated aging before it is clinically apparent. Some biomarkers may even offer a means by which interventions to reduce the rate of aging can be developed.
\end{abstract}

Keywords Comprehensive geriatric assessment $\cdot$ Frailty index $\cdot$ Frailty $\cdot$ Aging $\cdot$ Oncogeriatrics $\cdot$ Biomarkers $\cdot$ Epigenetics

\section{Introduction}

Sociopolitical modernization, breakthroughs that have improved early-age health, and lowered disease-specific mortality have yielded an aging global population, even in low- and middle-income countries [1,2]. Inasmuch as the "problems of old age come as a package," the growing population of older adults means more people with multiple, interacting social and medical problems [3]. Even so, contemporary disease-centric

This article is part of the Topical Collection on Geriatric Oncology

Kenneth Rockwood

Kenneth.Rockwood@nshealth.ca

Lucas W. M. Diebel

Lucas.diebel@nshealth.ca

1 Division of Geriatric Medicine, Department of Medicine, Dalhousie University, Nova Scotia Health Authority, Halifax, Canada

2 Centre for Health Care of the Elderly, Veterans' Memorial Building, 4121-5955 Veterans' Memorial Lane, Halifax, Nova Scotia B3H 2E9, Canada

3 Department of Medicine, Divisions of Geriatric Medicine \& Neurology, Dalhousie University, Nova Scotia Health Authority, Halifax, Canada approaches often spurn those older patients whose many other health issues exclude them from clinical trials, but not from being referred for treatment [4-6]. How to understand the role that aging plays in the diseases of aging, including cancer, has only recently gained acceptance [5].

Aging is the time-dependent functional decline of an organism at all levels, from nanoscopic to the whole person; it results in vulnerability to perturbation and increased risk of death [7]. This complex process lies at the intersection of genetics, biology, and the environment; it exhibits marked disparity between species and individuals [7]. Reflecting this complexity, chronological age fails to account for the heterogeneity with which individuals age; in consequence, concepts of "biological age" have emerged from the need to better account for this variability and are a major focus in geroscience research [8]. The advantages of measuring biological age over chronological age range from combating ageism and individualizing care to the generation of fluid and modifiable interfaces with the aging process. Biological age is a more complex construct, as it must account for the variable effects of time on individuals.

Determination and grading of frailty are core components of geriatric assessment and offer a means to quantify the risks associated with advanced biological age [9]. Progress in 
understanding the aging process at all levels, novel means of measuring these changes efficiently, and application of modern biostatistical methods to interpret these changes at a population level each have culminated in a landscape where increasingly accurate biomarkers of aging can be formulated [10]. Here we briefly review the development, utility, limitations, and future applications of these approaches.

\section{Comprehensive Geriatric Assessment}

Comprehensive geriatric assessment (CGA) is the systematic, multidimensional process of determining the medical, psychological, functional, and social needs of an older adult. Even so, "assessment" is something of a misnomer, and an unfortunate one, inasmuch as it connotes simple administrative classification. Instead, the idea was rooted in moving beyond diagnosis, so that CGA includes comprehensive, patient-centered management. It has two related goals: tailoring an individualized plan and estimating prognosis [11]. CGA is the principal tool of geriatric medicine, with established benefits spanning numerous health-care settings including oncogeriatrics $[12,13]$. To harness the established benefits of CGA in being more likely to be alive and at home 1 year after hospitalization [14-16] and in predicting beneficial and adverse treatment responses $[17,18]$ requires multidisciplinary expertise and time. Frailty quantification is a core component of CGA, because it contextualizes care for complex patients, can respond to change, and possesses powerful prognostic value [19]. For these reasons, frailty holds value beyond the confines of CGA.

\section{Frailty}

Similar to aging, frailty is the result of multilevel deterioration across interacting physiologic systems, resulting in diminished homeostatic reserve, and vulnerability to perturbation [19]. Bettering chronological age, frailty estimates variability in risk for a given person compared to others of the same age, making it a proxy of biological age [19].

Two main models of frailty exist. Each offers information about risk compared to others of the same age. Phenotypic frailty, comprising three or more cardinal features of weight loss, self-reported exhaustion, weak grip, slow gait, and low physical activity, independently predicts adverse outcomes and death in persons over the age of 65 [20]. This establishes frailty as a recognizable clinical entity, but without accounting for other factors that increase risk of adverse outcomes, such as dementia [19]. Approximating biological age obliges a graded, rather than binary, method of measuring frailty; for the frailty phenotype, six grades are possible (i.e., no to all five features being present). More commonly, however, two distinctions are made in addition to being frail: "robust" (no features) and "pre-frail" (one or two features). The deficit accumulation model of frailty reflects that at any age, as a person accumulates health deficits, they become more likely to experience a range of adverse outcomes, including death [21]. Interestingly, these health deficits can be signs, symptoms, laboratory markers, disease states, or functional impairments, so long as they are associated with health, increase with age, are not ubiquitous, and cover a range of physiologic systems [22]. The ratio of deficits present to deficits assessed is a frailty index $(\mathrm{FI})$, ranging anywhere from 0 (no deficits present) to, in theory, 1 (all deficits present), allowing frailty to be graded [21]. For a given frailty scale, there is a limit to the number of deficits that an individual can accumulate, approximately 0.7 , above which, a person generally cannot survive [23].

While deficits can be signs, symptoms, or diagnoses and extracted from CGAs with reproducible estimates of mortality risk [24], it is also possible to approximate frailty using laboratory tests (such as serum albumin) and common clinical measures (such as pulse pressure) [25]. This implies the plausibility of estimating biological age from combinations of biological markers, with obvious implications as new biomarkers for biological age become available. Including more variables in a given frailty scale, across numerous domains of deficits that interact to varying degrees, improves the predictive ability of a frailty scale [21]. Note that the degree to which each deficit influences the system as a whole varies. The deficits most strongly associated with death occur with deficits in high order functions such as incontinence, dementia, and immobility, validating their emphasis in CGA $[23,26]$.

More recently, frailty has been validated to predict diseasespecific risks, such as cardiovascular morbidity and mortality in patients with known or high risk of coronary artery disease, interestingly predicting as well as or even surpassing standard risk calculators such as the Framingham risk score [27]. This approach has been further validated in adding prognostic value in the assessment of older patients with cancer, helping to stratify treatment approaches beyond measuring performance status alone [28]. The frailty index behaves in an orderly enough fashion to be applied in preclinical models, as animals similarly accumulate deficits during the life course, catalyzing research in better understanding and modifying the biological aging process [29-31•]. The frailty index has comparative predictive value to "death clocks" derived from machine learning algorithms in mice [32].

A frailty index is useful for studying populations of older patients and where EMR data allow, can be incorporated into routine care to predict adverse outcomes upon admission to hospital and predict recovery course following acute health changes [33, 34]. Further, a questionnaire based on the CGA completed by care partners correlates well with CGA-derived FI [35].

Even so, in clinical care, numbers often translate quickest when out into words. The Clinical Frailty Scale (CFS) was 
developed to summarize the results of CGA and validated to correlate well ( $r=0.8$ ) with the frailty index and other assessment tools [36]. This clinical tool quantifies the baseline frailty state - by convention in acute care, 2 weeks prior to the current assessment - providing predictive information and facilitating communication about the degree of frailty between health-care providers [37]. Pragmatically, the CFS focuses on the cumulative impact of health deficits such as cognitive impairment, comorbidity, mobility (including exercise), and disability [36]. The scale chiefly has been validated in patients over the age of 65 , who have age-related and not singlesystem disabilities, and requires combination with clinical judgment to be used effectively. The importance of judiciousness has been heightened with recent attempts to use this tool for allocation of scarce health-care resources, as with the coronavirus disease 2019 pandemic [38].

Early descriptions of frailty acknowledged its importance in assessing variation in risk as a given age but assumed it to be a constant [39]. More recent research has validated frailty as a core clinical concept in assessing older adults and while representing the underlying rate of age-related accumulation of deficits, implies that this typically progressive state is dynamic and potentially modifiable [23]. Interventions that can modify frailty and by proxy the rate of biological aging include interventions grounded in the CGA [40] or with exercise [41], nutrition [42], and possibly pharmacologic or reverse pharmacologic interventions $[43 \bullet, 44]$. This is likely to inform future research on frailty treatment and prevention and thereby impact on biological aging. The scope of needed inquiry for understanding biological aging is immense. For example, given that antecedents of biological aging can begin as early as conception [45], there is potential for biomarkers to detect aberrant aging trajectories before the onset of any clinically measurable deficit. Whether to describe that variability in risk inherent in potentially variable aging trajectories as frailty is thus far unexplored. In due course, an empirical approach, rather than a semantic one, in how and what to measure as a deficit is likely to yield the greater understanding.

\section{Biomarkers of Aging}

The American Federation for Aging Research proposed that a biomarker of aging should predict the rate of aging, monitor basic processes that underlie the aging process, be repeatedly testable without harming the test subject, and work in both humans and laboratory animals. This is an ongoing challenge that no single biomarker has yet met [10]. Nonetheless, landmark papers have outlined key biological hallmarks (or pillars) of aging, characterized by their manifestation during normal aging, and the ability to be experimentally aggravated or ameliorated with resultant impacts on aging trajectory [5, 7]. These important features of aging have served as a spring board for many candidate biomarkers for biological age. As aging is complex, aging biomarkers can theoretically be derived from any level of the organism at which measurable agerelated changes occur. It may be most beneficial to propose a battery of biomarkers, rather than just a single one [46].

\section{Telomeres and Aging}

Telomeres are the protective caps found at the ends of genomic DNA. They comprise repeated DNA sequences and unique proteins that together create the telomere-binding complex. In this way, highly regulated telomerase activity can selectively maintain telomere length [47]. Telomere biology propels interest in aging biomarkers for several reasons. First, inherited defects in telomerase function are associated with age-associated human disease, most notably idiopathic pulmonary fibrosis, many cancers, diabetes, cardiovascular disease, and dementias [48]. Second, telomere length shortens with chronological age and predicts the onset of cellular senescence [47]. This age-related state of cell growth arrest remarkably is present across the life course [49, 50]. Finally, telomere length, as well as telomerase activity, is heritable in both humans and mice, suggesting that it could account for some of the genetic variation seen in the aging process [50-52].

Mean leukocyte telomere length (LTL) is one means of approximating overall telomere maintenance and correlates with circulating immune cell senescence [53]. In association analysis of a large cohort of persons in the general population, peripheral LTL was associated with higher mortality [53]. Interestingly, in the largest available epidemiological study of telomere length to date, telomere length shortened until the age of 75, after which age became positively associated with telomere length, and females in general had longer telomere lengths than males [54]. However, not all longitudinal studies have been able to reproduce the association with mortality [55]. Thus, a recent meta-analysis incorporating a variety of studies on telomere length associations with mortality was conducted and confirmed the association between telomere length and all-cause mortality, albeit with large interstudy heterogeneity, and ongoing difficulties in improving the precision of telomere length measuring techniques [56]. Notably, they similarly found that the magnitude of association became weaker for the oldest patients [56]. While the relationship between all-cause mortality and telomere length has been described, there has been less success in associating telomere length and frailty, possibly as a result of ethnic differences in telomere attrition and deficit accumulation, frailtyassociated apoptosis of cells with shorter telomeres, and physiologic deficits occurring only after a critical point of telomere shortening is reached [57-61]. 


\section{Epigenetics and the Epigenetic Clock}

Epigenetics is the study of DNA modifications that do not alter the DNA sequence [62•]. The most well described as a biomarker of biological age is DNA methylation. Chronological age has significant effects on DNA methylation levels in the human genome [62•]. Corresponding with advances in DNA methylation measurements and biostatistical methods, two models showed strong correlation between methylation profiles and chronological age and were named "epigenetic clocks" [63, 64].

The mechanism by which epigenetic clocks estimate chronological age can be obscure; this is not wholly unexpected, given their derivation from computer learning algorithms sorting through patterns of hundreds of methylation targets [62•]. Theories include alterations in development and agerelated epigenetic maintenance systems and DNA methylation as a response to oxidative or other age-related damage to DNA $[62 \cdot, 65]$. Excitingly, recent work suggests that epigenetic markers represent not just a biomarker but targets for reprogramming as a means of treating aging [66••]. Even so, the claim that the epigenetic clock is presently the most predictive and well-validated biomarker of biological age is disputed [67•].

DNA methylation is both genetically and environmentally driven. Offspring of supercentenarians (105-109 years old) demonstrate patterns of DNA methylation consistent with lower epigenetic age than do age-matched controls [68]. Similarly, twin studies have estimated that epigenetic age acceleration produce heritability estimates of around $40 \%$; interestingly, the overlap of methylation patterns diminishes both with age and between twins who either spend less of their lifetime together or whose health trajectories diverge [69]. Likewise, social and behavioral factors associated with longevity (e.g., high fish intake, moderate alcohol consumption, high education) directly correlate with epigenetic age [70 $71 \cdot]$.

Although the first epigenetic clock could reliably estimate chronological age and chronological-age independent mortality risk, it was not associated with common disease risk factors [72]. A later (2018) 2-step model was used to create a novel DNA methylation informed biomarker. It was grounded in a composite of clinical markers of biological age and yielded enhanced predictions of mortality and age-related disease; even so, it was less predictive than the clinical markers used to create the model [73]. Subsequently, by differentiating the effects of chronological and phenotypic age using clinical chemistry biomarkers, this same group was able to approximate phenotypic age acceleration and found this "phenotypic age" to exceed chronological age in association with all-cause and cause-specific mortality [74]. A major advantage of this method is the ability to identify individuals at risk who are apparently healthy, and at younger ages, before the onset of clinically measurable age-related deficits [74]. This marker will require further validation in longitudinal studies [74]. The relationship between epigenetic clocks and the frailty index is unfolding, but many studies show greater discriminative ability in relation to mortality of the latter [67, 75-77].

\section{“Omics"-Based Biomarkers}

Transcriptomics is the study of the transcriptional output of an organism's genome. The transcriptome encompasses the full range of RNA and mRNA expressed at a given time, is highly dynamic, and is responsive to environmental changes [78]. A 2015 large-scale meta-analysis of age-related gene expression profiles offered a transcriptomic-based age predictor [79]. Functional clusters of genes, identified as up- or downregulated with aging, with concomitant assessment of epigenetic markers correlated with other hallmarks of aging [7]. Although transcriptomic age correlated well with epigenetic age, it was less well correlated to chronological age. Notably, the combination of these transcriptional and epigenetic markers led to synergism, so that the combination outperformed either marker alone [79].

Proteomics offers a comprehensive, quantitative description of the sum of protein expression in an organism and demonstrates influence by perturbation [80]. An array of proteins are differentially expressed as humans advance from neonates to adults [81]. A twin-based cohort study identified four replicating proteins that were independently associated with chronological age [82. These proteins, particularly CHRDL1, correlated directly with higher birth weight and inversely with cardiovascular risk. This field offers promise in developing predictors of biological age.

Metabonomics studies the metabolic responses of living systems to manipulation [83]. Building on the success of metabonomics in predicting common age-related disorders, a metabolic age score using 59 urinary metabolites was tested in predicting biological age in two large, cross-sectional population-based samples [84]. While proving the concept that meaningful metabolic information can estimate age, its derivation from cross-sectional data means it cannot yet estimate the metabonomic changes of aging at the individual level [84].

\section{Combining Biomarkers}

Approximation of biological age using data from a single level of an organism may be inherently limited due to the essence of aging as a complex process occurring at all levels of an organism. Theoretically, embracing this complexity by utilizing biomarkers from multiple levels of an organism would improve the accuracy of such a measurement. The MARKAGE study will attempt to address question, using a study 
population of 3200 subjects and incorporating a broad range of aging biomarkers ranging from physiologic parameters such as heart rate and blood pressure at rest to DNA methylation-based markers [85].

Interestingly, the MARK-AGE project has been developed independently of - or felt it best to steer clear of - frailty. Notably, however, a frailty index can combine items across levels, to result in improved performance in predicting adverse outcomes $[25,86,87]$.

\section{Conclusions}

Chronological age is rigid and fails to account for the variable effects of time on individuals. The construct of "biological age" aims to give a more ordered relation between an individual's current health state and their proximity to death. This in turn can enable a novel approach to individualizing care and potentially yield ways in which aging might be modified. The manifold manifestations of aging, from subcellular to organismal, have motivated diverse approaches to its measurement.

A quantitative approach to frailty yields a proxy measure of biological age that can be formulated from deficit accumulation indices and geriatric assessment. The great advantage of this approach is that it offers information that is immediately relevant to guiding treatment strategies and estimating prognosis. Biomarkers derived from the mechanistic underpinnings of aging hold out the promise of measuring processes of aging before clinically recognizable deficits ensue. So doing, they can complement the information about individuals' health that is required for appropriate care planning and that can readily be summarized in a frailty index. These clinically derived frailty indices can outperform measures of biological age in predicting proximity to death without incorporating chronological age into their measurement [67, 75-77]. Furthermore, the cost of routinely performing sophisticated biomarker-based measures of biological age is prohibitive.

Complementarity of biomarkers and frailty indices can be demonstrated through both measures used simultaneously or by being combined [76•]. Further, frailty indices can use biomarkers as deficits, even when normal ranges have not been established for that purpose [88]. In ways like this, the siloed approach to biological biomarkers can be overcome, and perhaps enhanced, through their combination with frailty measures that are likely already to be in the clinical record or that can feasibly be derived from it.

Already, classically "healthy" behaviors correspond with deceleration of the biological biomarkers of aging [70, 71]. Preclinical animal models of biological aging using frailty or other biomarkers have created experimental interfaces through which the aging trajectory can be modified [66, 89•]. This notably includes the exciting possibility of treating the biomarker of DNA methylation so as to arrive at younger phenotypes [66]. Promising interventions have the potential to slow aging and delay or mitigate the onset of disabling, chronic diseases associated with age, including cancer and neurodegeneration [90]. Even so, it remains that any marker of age, regardless of accuracy, must be seen in the context of each person's psychosocial environment.

\section{Declarations}

Conflict of Interest Kenneth Rockwood has asserted copyright of the Clinical Frailty Scale through Dalhousie University's Industry, Liaison, and Innovation Office. Use is free for education, research, and not-forprofit health care. Users agree not to change or commercialize the scale. In addition to academic and hospital appointments, Kenneth Rockwood is Co-founder of Ardea Outcomes, which (as DGI Clinical) in the last 3 years has contracts with pharma and device manufacturers (Hollister, Novartis, Nutricia, Roche, Takeda) on individualized outcome measurement. In 2020, he attended an advisory board meeting with Nutricia on dementia and chaired a Scientific Workshop \& Technical Review Panel on frailty for the Singapore National Research Foundation. Otherwise, any personal fees are for invited guest lectures, rounds, and academic symposia, received directly from event organizers, for presentations on frailty. He is the Associate Director of the Canadian Consortium on Neurodegeneration in Aging, which is funded by the Canadian Institutes of Health Research, the Alzheimer Society of Canada, and several other charities.

Lucas Diebel declares he has no conflict of interest.

Human and Animal Rights and Informed Consent This article does not contain any studies with human or animal subjects performed by any of the authors.

\section{References}

Papers of particular interest, published recently, have been highlighted as:

- Of importance

•• Of major importance

1. Crimmins EM. Lifespan and healthspan: past, present, and promise. Gerontologist. 2015;55(6):901-11. https://doi.org/10.1093/geront/ gnv130.

2. United Nations. Department of Economic and Social Affairs, Population Division (2019). World population prospects. 2019; highlights (ST/ESA/SER.A/423).

3. Fontana L, Kennedy BK, Longo VD, Seals D, Melov S. Medical research: treat ageing. Nature. 2014;511(7510):405-7. https://doi. org/10.1038/511405a.

4. Zulman DM, Sussman JB, Chen X, Cigolle CT, Blaum CS, Hayward RA. Examining the evidence: a systematic review of the inclusion and analysis of older adults in randomized controlled trials. J Gen Intern Med. 2011;26(7):783-90. https://doi.org/10. 1007/s11606-010-1629-x.

5. Kennedy BK, Berger SL, Brunet A, Campisi J, Cuervo AM, Epel ES, et al. Geroscience: linking aging to chronic disease. Cell. 2014;159(4):709-13. https://doi.org/10.1016/j.cell.2014.10.039.

6. Vos T, Flaxman AD, Naghavi M, Lozano R, Michaud C, Ezzati M, et al. Years lived with disability (YLDs) for 1160 sequelae of 289 
diseases and injuries 1990-2010: a systematic analysis for the Global Burden of Disease Study 2010. Lancet. 2012;380(9859): 2163-96. https://doi.org/10.1016/S0140-6736(12)61729-2.

7. López-Otín C, Blasco MA, Partridge L, Serrano M, Kroemer G. The hallmarks of aging. Cell. 2013;153(6):1194-217. https://doi. org/10.1016/j.cell.2013.05.039.

8. Lowsky DJ, Olshansky SJ, Bhattacharya J, Goldman DP. Heterogeneity in healthy aging. J Gerontol A Biol Sci Med Sci. 2014;69(6):640-9. https://doi.org/10.1093/gerona/glt162.

9. Morley JE, Vellas B, van Kan GA, Anker SD, Bauer JM, Bernabei R, et al. Frailty consensus: a call to action. J Am Med Dir Assoc. 2013;14(6):392-7. https://doi.org/10.1016/j.jamda.2013.03.022.

10. Jylhävä J, Pedersen NL, Hägg S. Biological age predictors. EBioMedicine. 2017;21:29-36. https://doi.org/10.1016/j.ebiom. 2017.03.046.

11. Rubenstein LZ, Rubenstein LV. Multidimensional geriatric assessment. In: Fillit HM, Rockwood K, Young J, editors. Brocklehurst's Textbook of Geriatric Medicine and Gerontology. Elsevier Inc.; 2017. pp. 213-219.

12. Extermann M, Aapro M, Bernabei R, Cohen HJ, Droz JP, Lichtman $\mathrm{S}$, et al. Task Force on CGA of the International Society of Geriatric Oncology. Use of comprehensive geriatric assessment in older cancer patients: recommendations from the task force on CGA of the International Society of Geriatric Oncology (SIOG). Crit Rev Oncol Hematol. 2005;55(3):241-52. https://doi.org/10.1016/j. critrevonc.2005.06.003.

13. Wildiers H, Heeren P, Puts M, Topinkova E, Janssen-Heijnen ML, Extermann M, et al. International Society of Geriatric Oncology consensus on geriatric assessment in older patients with cancer. J Clin Oncol. 2014;32(24):2595-603. https://doi.org/10.1200/JCO. 2013.54.8347.

14. Ellis G, Gardner M, Tsiachristas A, Langhorne P, Burke O, Harwood RH, et al. Comprehensive geriatric assessment for older adults admitted to hospital. Cochrane Database Syst Rev. 2017;9(9):CD006211. https://doi.org/10.1002/14651858. CD006211.pub3.

15. Eamer G, Taheri A, Chen SS, Daviduck Q, Chambers T, Shi X, et al. Comprehensive geriatric assessment for older people admitted to a surgical service. Cochrane Database Syst Rev. 2018;1(1): CD012485. https://doi.org/10.1002/14651858.CD012485.pub2.

16. Partridge JS, Harari D, Martin FC, Peacock JL, Bell R, Mohammed A, et al. Randomized clinical trial of comprehensive geriatric assessment and optimization in vascular surgery. Br J Surg. 2017;104(6):679-87. https://doi.org/10.1002/bjs.10459.

17. Corre R, Greillier L, Le Caër H, Audigier-Valette C, Baize N, Bérard $\mathrm{H}$, et al. Use of a comprehensive geriatric assessment for the management of elderly patients with advanced non-small-cell lung cancer: the phase III randomized ESOGIA-GFPC-GECP 0802 study. J Clin Oncol. 2016;34(13):1476-83. https://doi.org/10. 1200/JCO.2015.63.5839.

18. Palumbo A, Bringhen S, Mateos MV, Larocca A, Facon T, Kumar SK, et al. Geriatric assessment predicts survival and toxicities in elderly myeloma patients: an International Myeloma Working Group report. Blood. 2015;125(13):2068-74. https://doi.org/10. 1182/blood-2014-12-615187.

19. Clegg A, Young J, Iliffe S, Rikkert MO, Rockwood K. Frailty in elderly people. Lancet. 2013;382(9901):1328-762. https://doi.org/ 10.1016/S0140-6736(12)62167-9.

20. Fried LP, Tangen CM, Walston J, Newman AB, Hirsch C, Gottdiener J, et al. Frailty in older adults: evidence for a phenotype. J Gerontol A Biol Sci Med Sci. 2001;56(3):M146-56. https://doi. org/10.1093/gerona/56.3.m146.

21. Mitnitski AB, Mogilner AJ, Rockwood K. Accumulation of deficits as a proxy measure of aging. Sci World J. 2001;1:323-36. https:// doi.org/10.1100/tsw.2001.58.
22. Searle SD, Mitnitski A, Gahbauer EA, Gill TM, Rockwood K. A standard procedure for creating a frailty index. BMC Geriatr. 2008;8:24. https://doi.org/10.1186/1471-2318-8-24.

23. Rutenberg AD, Mitnitski AB, Farrell SG, Rockwood K. Unifying aging and frailty through complex dynamical networks. Exp Gerontol. 2018;107:126-9. https://doi.org/10.1016/j.exger.2017. 08.027 .

24. Jones DM, Song X, Rockwood K. Operationalizing a frailty index from a standardized comprehensive geriatric assessment. J Am Geriatr Soc. 2004;52(11):1929-33. https://doi.org/10.1111/j.15325415.2004.52521.x.

25. Blodgett JM, Theou O, Howlett SE, Rockwood K. A frailty index from common clinical and laboratory tests predicts increased risk of death across the life course. Geroscience. 2017;39(4):447-55. https://doi.org/10.1007/s11357-017-9993-7.

26. Morley JE. A brief history of geriatrics. J Gerontol A Biol Sci Med Sci. 2004;59(11):1132-52. https://doi.org/10.1093/gerona/59.11. 1132.

27. Farooqi MAM, Gerstein H, Yusuf S, Leong DP. Accumulation of deficits as a key risk factor for cardiovascular morbidity and mortality: a pooled analysis of 154000 individuals. J Am Heart Assoc. 2020;9(3):e014686. https://doi.org/10.1161/JAHA.119.014686.

28. Ferrat E, Paillaud E, Caillet P, Laurent M, Tournigand C, Lagrange $\mathrm{JL}$, et al. Performance of four frailty classifications in older patients with cancer: prospective elderly cancer patients cohort study. J Clin Oncol. 2017;35(7):766-77. https://doi.org/10.1200/JCO.2016.69. 3143.

29. Whitehead JC, Hildebrand BA, Sun M, Rockwood MR, Rose RA, Rockwood K, et al. A clinical frailty index in aging mice: comparisons with frailty index data in humans. J Gerontol A Biol Sci Med Sci. 2014;69(6):621-32. https://doi.org/10.1093/gerona/glt136.

30. Heinze-Milne SD, Banga S, Howlett SE. Frailty assessment in animal models. Gerontology. 2019;65(6):610-9. https://doi.org/10. $1159 / 000501333$.

31. Rockwood K, Blodgett JM, Theou O, Sun MH, Feridooni HA, Mitnitski A, et al. A frailty index based on deficit accumulation quantifies mortality risk in humans and in mice. Sci Rep, The deficit accumulation model of frailty can be applied to mice to facilitate translational research on aging. 2017;7:43068. https:// doi.org/10.1038/srep43068.

32. Schultz MB, Kane AE, Mitchell SJ, MacArthur MR, Warner E, Vogel DS, et al. Age and life expectancy clocks based on machine learning analysis of mouse frailty. Nat Commun. 2020;11(1):4618. https://doi.org/10.1038/s41467-020-18446-0.

33. Hubbard RE, Eeles EM, Rockwood MR, Fallah N, Ross E, Mitnitski A, et al. Assessing balance and mobility to track illness and recovery in older inpatients. J Gen Intern Med. 2011;26(12): 1471-8. https://doi.org/10.1007/s11606-011-1821-7.

34. Hubbard RE, Peel NM, Samanta M, Gray LC, Mitnitski A, Rockwood K. Frailty status at admission to hospital predicts multiple adverse outcomes. Age Ageing. 2017;46(5):801-6. https:// doi.org/10.1093/ageing/afx081.

35. Goldstein J, Hubbard RE, Moorhouse P, Andrew MK, Mitnitski A, Rockwood $\mathrm{K}$. The validation of a care partner-derived frailty index based upon comprehensive geriatric assessment (CP-FI-CGA) in emergency medical services and geriatric ambulatory care. Age Ageing. 2015;44(2):327-30. https://doi.org/10.1093/ageing/ afu161.

36. Rockwood K, Song X, MacKnight C, Bergman H, Hogan DB, McDowell I, et al. A global clinical measure of fitness and frailty in elderly people. CMAJ. 2005;173(5):489-95. https://doi.org/10. 1503/cmaj.050051.

37. Jarrett PG, Rockwood K, Carver D, Stolee P, Cosway S. Illness presentation in elderly patients. Arch Intern Med. 1995;155(10): 1060-4. 
38. Rockwood K, Theou O. Using the Clinical Frailty Scale in allocating scarce health care resources. Can Geriatr J. 2020;23(3):210-5. https://doi.org/10.5770/cgj.23.463.

39. Vaupel JW, Manton KG, Stallard E. The impact of heterogeneity in individual frailty on the dynamics of mortality. Demography. 1979;16(3):439-54.

40. Mazya AL, Garvin P, Ekdahl AW. Outpatient comprehensive geriatric assessment: effects on frailty and mortality in old people with multimorbidity and high health care utilization. Aging Clin Exp Res. 2019;31(4):519-25. https://doi.org/10.1007/s40520-0181004-z.

41. de Labra C, Guimaraes-Pinheiro C, Maseda A, Lorenzo T, MillánCalenti JC. Effects of physical exercise interventions in frail older adults: a systematic review of randomized controlled trials. BMC Geriatr. 2015;15:154. https://doi.org/10.1186/s12877-015-0155-4.

42. Cruz-Jentoft AJ, Kiesswetter E, Drey M, Sieber CC. Nutrition, frailty, and sarcopenia. Aging Clin Exp Res. 2017;29(1):43-8. https://doi.org/10.1007/s40520-016-0709-0.

43. Espinoza SE, Musi N, Wang CP, Michalek J, Orsak B, Romo T, et al. Rationale and study design of a randomized clinical trial of metformin to prevent frailty in older adults with prediabetes. J Gerontol A Biol Sci Med Sci. 2020;75(1):102-9. https://doi.org/ 10.1093/gerona/glz078 One of the first randomized trials using a pharmacologic intervention to prevent frailty in older adults, as measured by the onset of a composite of age-related conditions, including cancer.

44. Potter K, Flicker L, Page A, Etherton-Beer C. Deprescribing in frail older people: a randomised controlled trial. PLoS One. 2016;11(3): e0149984. https://doi.org/10.1371/journal.pone.0149984.

45. Allison BJ, Kaandorp JJ, Kane AD, Camm EJ, Lusby C, Cross CM, et al. Divergence of mechanistic pathways mediating cardiovascular aging and developmental programming of cardiovascular disease. FASEB J. 2016;30(5):1968-75. https://doi.org/10.1096/fj. 201500057.

46. Muscedere J, Kim PM, Afilalo J, Balion C, Baracos VE, Bowdish D, et al. Proceedings of the Canadian Frailty Network Workshop: Identifying Biomarkers of Frailty to Support Frailty Risk Assessment, Diagnosis and Prognosis. Toronto January 152018. J Frailty Aging. 2019;8(3):106-16. https://doi.org/10.14283/jfa. 2019.12.

47. Armanios M. Telomeres and age-related disease: how telomere biology informs clinical paradigms. J Clin Invest. 2013;123(3): 996-1002. https://doi.org/10.1172/JCI66370.

48. Armanios M, Blackburn EH. The telomere syndromes. Nat Rev Genet. 2012;13(10):693-704. https://doi.org/10.1038/nrg3246.

49. van Deursen JM. The role of senescent cells in ageing. Nature. 2014;509(7501):439-46. https://doi.org/10.1038/nature13193.

50. Muñoz-Lorente MA, Cano-Martin AC, Blasco MA. Mice with hyper-long telomeres show less metabolic aging and longer lifespans. Nat Commun. 2019;10(1):4723. https://doi.org/10. 1038/s41467-019-12664-x.

51. Calado RT, Dumitriu B. Telomere dynamics in mice and humans. Semin Hematol. 2013;50(2):165-74. https://doi.org/10.1053/j. seminhematol.2013.03.030.

52. Blackburn EH, Epel ES, Lin J. Human telomere biology: a contributory and interactive factor in aging, disease risks, and protection. Science. 2015;350(6265):1193-8. https://doi.org/10.1126/science. aab3389.

53. Rode L, Nordestgaard BG, Bojesen SE. Peripheral blood leukocyte telomere length and mortality among 64,637 individuals from the general population. J Natl Cancer Inst. 2015;107(6):djv074. https:// doi.org/10.1093/jnci/djv074.

54. Lapham K, Kvale MN, Lin J, Connell S, Croen LA, Dispensa BP, et al. Automated assay of telomere length measurement and informatics for 100,000 subjects in the Genetic Epidemiology Research on Adult Health and Aging (GERA) cohort. Genetics. 2015;200(4): 1061-72. https://doi.org/10.1534/genetics.115.178624.

55. Bendix L, Thinggaard M, Fenger M, Kolvraa S, Avlund K, Linneberg A, et al. Longitudinal changes in leukocyte telomere length and mortality in humans. J Gerontol A Biol Sci Med Sci. 2014;69(2):231-9. https://doi.org/10.1093/gerona/glt153.

56. Wang Q, Zhan Y, Pedersen NL, Fang F, Hägg S. Telomere length and all-cause mortality: a meta-analysis. Ageing Res Rev. 2018;48: 11-20. https://doi.org/10.1016/j.arr.2018.09.002.

57. Breitling LP, Saum KU, Perna L, Schöttker B, Holleczek B, Brenner H. Frailty is associated with the epigenetic clock but not with telomere length in a German cohort. Clin Epigenetics. 2016;8: 21. https://doi.org/10.1186/s13148-016-0186-5.

58. Zhou J, Wang J, Shen Y, Yang Y, Huang P, Chen S, et al. The association between telomere length and frailty: a systematic review and meta-analysis. Exp Gerontol. 2018;106:16-20. https://doi.org/ 10.1016/j.exger.2018.02.030.

59. Araújo Carvalho AC, Tavares Mendes ML, da Silva Reis MC, Santos VS, Tanajura DM, Martins-Filho PRS. Telomere length and frailty in older adults-a systematic review and meta-analysis. Ageing Res Rev. 2019;54:100914. https://doi.org/10.1016/j.arr. 2019.100914

60. Lorenzi M, Bonassi S, Lorenzi T, Giovannini S, Bernabei R, Onder G. A review of telomere length in sarcopenia and frailty. Biogerontology. 2018;19(3-4):209-21. https://doi.org/10.1007/ s10522-018-9749-5.

61. Blackburn EH. Telomere states and cell fates. Nature. 2000;408(6808):53-6. https://doi.org/10.1038/35040500.

62. Horvath S, Raj K. DNA methylation-based biomarkers and the epigenetic clock theory of ageing. Nat Rev Genet. 2018;19(6): 371-84. https://doi.org/10.1038/s41576-018-0004-3 Biomarkers of aging based on DNA methylation enable accurate age estimates across the entire life course.

63. Horvath S. DNA methylation age of human tissues and cell types. Genome Biol. 2013;14(10):R115. https://doi.org/10.1186/gb-201314-10-r115.

64. Hannum G, Guinney J, Zhao L, Zhang L, Hughes G, Sadda S, et al. Genome-wide methylation profiles reveal quantitative views of human aging rates. Mol Cell. 2013;49(2):359-67. https://doi.org/10. 1016/j.molcel.2012.10.016.

65. Morano A, Angrisano T, Russo G, Landi R, Pezone A, Bartollino $\mathrm{S}$, et al. Targeted DNA methylation by homology-directed repair in mammalian cells. Transcription reshapes methylation on the repaired gene. Nucleic Acids Res. 2014;42(2):804-21. https://doi. org/10.1093/nar/gkt920.

66. Lu Y, Brommer B, Tian X, Krishnan A, Meer M, Wang C, et al. Reprogramming to recover youthful epigenetic information and restore vision. Nature. 2020;588(7836):124-9. https://doi.org/10. 1038/s41586-020-2975-4 Experimental evidence that epigenetic reprogramming could reverse age-related decline and restore function in aged CNS neurons using an eye model.

67. Kim S, Myers L, Wyckoff J, Cherry KE, Jazwinski SM. The frailty index outperforms DNA methylation age and its derivatives as an indicator of biological age. Geroscience. 2017;39(1):83-92. https:// doi.org/10.1007/s11357-017-9960-3 Frailty index outperforms DNA methylation age in predicting biological age.

68. Horvath S, Pirazzini C, Bacalini MG, Gentilini D, Di Blasio AM, Delledonne $\mathrm{M}$, et al. Decreased epigenetic age of PBMCs from Italian semi-supercentenarians and their offspring. Aging (Albany NY). 2015;7(12):1159-70. https://doi.org/10.18632/aging.100861.

69. Fraga MF, Ballestar E, Paz MF, Ropero S, Setien F, Ballestar ML, et al. Epigenetic differences arise during the lifetime of monozygotic twins. Proc Natl Acad Sci U S A. 2005;102(30):10604-9. https:// doi.org/10.1073/pnas.0500398102.

70. Quach A, Levine ME, Tanaka T, Lu AT, Chen BH, Ferrucci L, et al. Epigenetic clock analysis of diet, exercise, education, and 
lifestyle factors. Aging (Albany NY). 2017;9(2):419-46. https:// doi.org/10.18632/aging.101168 Lifestyle factors influence the rate of biological aging using epigenetic markers.

71. Fiorito G, McCrory C, Robinson O, Carmeli C, Rosales CO, Zhang $\mathrm{Y}$, et al. Socioeconomic position, lifestyle habits and biomarkers of epigenetic aging: a multi-cohort analysis. Aging (Albany NY). 2019;11(7):2045-70. https://doi.org/10.18632/aging.101900 Socioeconomic position has comparable effects to obesity and alcohol consumption in driving biological aging as measured by epigenetic markers.

72. Horvath S, Gurven M, Levine ME, Trumble BC, Kaplan H, Allayee $\mathrm{H}$, et al. An epigenetic clock analysis of race/ethnicity, sex, and coronary heart disease. Genome Biol. 2016;17(1):171. https://doi.org/10.1186/s13059-016-1030-0.

73. Levine ME, Lu AT, Quach A, Chen BH, Assimes TL, Bandinelli S, et al. An epigenetic biomarker of aging for lifespan and healthspan. Aging (Albany NY). 2018;10(4):573-91. https://doi.org/10.18632/ aging. 101414 .

74. Liu Z, Kuo PL, Horvath S, Crimmins E, Ferrucci L, Levine M. A new aging measure captures morbidity and mortality risk across diverse subpopulations from NHANES IV: a cohort study. PLoS Med. 2018;15(12):e1002718. https://doi.org/10.1371/journal. pmed.1002718.

75. Mitnitski A, Howlett SE, Rockwood K. Heterogeneity of human aging and its assessment. J Gerontol A Biol Sci Med Sci. 2017;72(7):877-84. https://doi.org/10.1093/gerona/glw089.

76. Li X, Ploner A, Wang Y, Magnusson PK, Reynolds C, Finkel D, et al. Longitudinal trajectories, correlations and mortality associations of nine biological ages across 20-years follow-up. Elife. 2020;9:e51507. https://doi.org/10.7554/eLife.51507 Frailty index and DNA methylation-based biomarkers of aging were strongest predictors of mortality and were even more powerful when combined.

77. Jazwinski SM, Kim S. Examination of the dimensions of biological age. Front Genet. 2019;10:263. https://doi.org/10.3389/fgene.2019. 00263.

78. Pertea M. The human transcriptome: an unfinished story. Genes (Basel). 2012;3(3):344-60. https://doi.org/10.3390/genes3030344.

79. Peters MJ, Joehanes R, Pilling LC, Schurmann C, Conneely KN, Powell J, et al. The transcriptional landscape of age in human peripheral blood. Nat Commun. 2015;6:8570. https://doi.org/10. 1038/ncomms9570.

80. Anderson NL, Anderson NG. Proteome and proteomics: new technologies, new concepts, and new words. Electrophoresis. 1998;19(11):1853-61.
81. Ignjatovic V, Lai C, Summerhayes R, Mathesius U, Tawfilis S, Perugini MA, et al. Age-related differences in plasma proteins: how plasma proteins change from neonates to adults. PLoS One. 2011;6(2):e17213. https://doi.org/10.1371/journal.pone.0017213.

82. Menni C, Kiddle SJ, Mangino M, Viñuela A, Psatha M, Steves C, et al. Circulating proteomic signatures of chronological age. J Gerontol A Biol Sci Med Sci. 2015;70(7):809-16. https://doi.org/ 10.1093/gerona/glu121.

83. Nicholson JK, Lindon JC. Systems biology: metabonomics. Nature. 2008 Oct 23;455(7216):1054-6. https://doi.org/10.1038/ $4551054 a$.

84. Hertel J, Friedrich N, Wittfeld K, Pietzner M, Budde K, Van der Auwera S, et al. Measuring biological age via metabonomics: the metabolic age score. J Proteome Res. 2016;15(2):400-10. https:// doi.org/10.1021/acs.jproteome.5b00561.

85. Bürkle A, Moreno-Villanueva M, Bernhard J, Blasco M, Zondag G, Hoeijmakers JH, et al. MARK-AGE biomarkers of ageing. Mech Ageing Dev. 2015;151:2-12. https://doi.org/10.1016/j.mad. 2015.03.006.

86. Rockwood K, McMillan M, Mitnitski A, Howlett SE. A frailty index based on common laboratory tests in comparison with a clinical frailty index for older adults in long-term care facilities. J Am Med Dir Assoc. 2015;16(10):842-7. https://doi.org/10.1016/j. jamda.2015.03.027.

87. Mitnitski A, Collerton J, Martin-Ruiz C, Jagger C, von Zglinicki T, Rockwood K, et al. Age-related frailty and its association with biological markers of ageing. BMC Med. 2015;13:161. https:// doi.org/10.1186/s12916-015-0400-x.

88. Stubbings G, Farrell S, Mitnitski A, Rockwood K, Rutenberg A. Informative frailty indices from binarized biomarkers. Biogerontology. 2020;21(3):345-55. https://doi.org/10.1007/ s10522-020-09863-1.

89. Banga S, Heinze-Milne SD, Howlett SE. Rodent models of frailty and their application in preclinical research. Mech Ageing Dev. 2019;179:1-10. https://doi.org/10.1016/j.mad.2019.01.008 Preclinical models of frailty have demonstrated that lifestyle and pharmacologic interventions can impact frailty.

90. Partridge L, Fuentealba M, Kennedy BK. The quest to slow ageing through drug discovery. Nat Rev Drug Discov. 2020;19(8):513-32. https://doi.org/10.1038/s41573-020-0067-7.

Publisher's Note Springer Nature remains neutral with regard to jurisdictional claims in published maps and institutional affiliations. 